\title{
Meetings and More Meetings: The Relationship Between Meeting Load and the Daily Well-Being of Employees
}

\author{
Alexandra Luong \\ University of Minnesota Duluth
}

\author{
Steven G. Rogelberg \\ University of North Carolina at Charlotte
}

\begin{abstract}
Meetings are an integral part of organizational life; however, few empirical studies have systematically examined the phenomenon and its effects on employees. By likening work meetings to interruptions and daily hassles, the authors proposed that meeting load (i.e., frequency and time spent) can affect employee well-being. For a period of 1 week, participants maintained daily work diaries of their meetings as well as daily self-reports of their well-being. Using hierarchical linear modeling analyses, the authors found a significant positive relationship between number of meetings attended and daily fatigue as well as subjective workload (i.e., more meetings were associated with increased feelings of fatigue and workload).
\end{abstract}

Meetings are an integral and pervasive experience of organizational life. As a forum in which employees communicate and coordinate the organization's goals and objectives, the meeting is a vehicle for many activities, from problem solving to interdepartmental interactions. Given their utility, it is not surprising that meeting load (i.e., the frequency and length of meetings) has steadily surged in the last few decades (Mosvick \& Nelson, 1987). Since a 1973 study by Mintzberg, which found that the majority of a manager's typical workday $(69 \%)$ was spent in meetings, more recent surveys have suggested that meeting loads are increasing. Mosvick and Nelson (1987), for example, reported that relative to the 1960 s, the average executive participated in twice as many meetings in the 1980s. Tobia and Becker (1990), in a survey of 1,900 business leaders, found that almost $72 \%$ of individuals currently spend more

Alexandra Luong, Department of Psychology, University of Minnesota Duluth; Steven G. Rogelberg, Department of Psychology, University of North Carolina at Charlotte.

The research described here was supported with funds from an Academic Challenge Grant awarded to the Industrial-Organizational Psychology Program at Bowling Green State University by the Ohio Board of Regents. We thank Peter Warr and Des Leach for their insightful comments on a draft of this article.

Correspondence concerning this article should be addressed to Alexandra Luong, Department of Psychology, University of Minnesota Duluth, 320 Bohannon Hall, 1207 Ordean Court, Duluth, MN 55812. E-mail: aluong@ d.umn.edu time in meetings than they did 5 years ago. In addition, more than $49 \%$ surveyed expect to be spending even more time in meetings 4 years from now.

Given these statistics indicating the rise in frequency of and time spent in meetings, it behooves us to ask whether increased meeting load is indeed beneficial for the organization and the individual employee. To the extent that meetings help organizations and employees achieve their goals, their utility is quite apparent. The question remains, however, as to whether an ever-increasing meeting load may affect the employee at the individual, psychological level. In our search of the extant literature, we found no research that addresses the psychological effects of meeting load; in fact, we found that few empirical studies have been conducted on the phenomenon of the meeting itself. In taking heed of Schwartzman's (1986) declaration to examine the meeting as a topic in its own right, with the present study we attempt to contribute to research by examining the meeting load of a sample of employees and how it affects how these employees feel at the end of each day, for 5 days.

We propose that despite the fact that meetings may help achieve work-related goals, having too many meetings and spending too much time in meetings per day may have negative effects on the individual. In other words, we fully acknowledge the work-related benefits and the utility of meetings, but we further suggest a main effect for meeting load on the individual at 
the end of each day. These end-of-day outcomes, which we refer to as daily well-being, include factors such as fatigue, perceptions of workload, and feelings of productivity. These variables have been the criteria of interest in many studies on stress and psychological wellbeing (e.g., Caspi, Bolger, \& Eckenrode, 1987; DiLorenzo, Bovbjerg, Montgomery, Valdimarsdottir, \& Jacobsen, 1999; Ganster \& Schaubroeck, 1991; Jamal, 1990). Before we discuss the premises for our hypotheses, we first provide a review of the theory and research underlying our study.

\section{Meetings as Interruptions and Hassles}

As stated previously, the primary goal of our study is to examine whether meeting load relates to the daily well-being of employees. The specific hypotheses forwarded are based on the daily hassles and interruptions literature. We first describe this literature and then forward the notion that meetings may serve as hassles and interruptions for employees.

\section{Daily Hassles}

Defined in the stress research literature as "annoying episodes in which daily tasks become more difficult or demanding than anticipated," hassles have been found to predict stress symptoms better than most other predictor variables (Zohar, 1999, p. 265). Varying from equipment malfunction to inappropriate behavior of coworkers (Zohar, 1999), such obstacles predict an array of stress-related effects, including burnout (Zohar, 1997), anxiety, depression, and other negative emotions (Koch, Tung, Gmelch, \& Swent, 1982; Motowidlo, Packard, \& Manning, 1986). In a recent study, Zohar (1999) examined the effects of occupational hassles on negative mood and exertion in a sample of parachute trainers. Work hassles faced by the participants (e.g., equipment failure, administrative hassles) were provided by daily records. Using pooled-time series analysis, Zohar found that severity of hassles predicted end-of-day mood, fatigue, and subjective workload.

Several theories have been put forth to explain the effects of hassles. In his summary, Zohar (1999) suggested that these explanations can all fall under the rubric of action theory, which proposes that hassles cause negative effects because they prevent or delay the individual from reaching his or her goal. Specifically, when an ongoing activity is interrupted by an external factor, the individual must then exert greater effort in trying to overcome the obstacle. This greater exertion of effort then depletes the resources for the primary task, which may result in increased fatigue and negative mood. In addition, negative mood can also occur because the rate of progress toward completion of the primary task has been slowed. Based on research showing that progress toward personal goals affects emotional reactions (e.g., Emmons, 1986, 1991), the premise of this explanation is that negative mood is induced when the rate of progress toward completion of a task is slower than anticipated. Hence, hassles are expected to produce negative moods because they impede the progress toward a goal.

\section{Interruptions}

The early work of Zeigarnik and her colleagues (see Butterfield, 1964, for a review) found that when participants were prevented from finishing a task, they resumed the task when given the freedom to do so. In addition, interrupted tasks were recalled more frequently than finished tasks (Butterfield, 1964). In a 1988 study, Kirmeyer used an observational recording system whereby the objective assessment of the workload of police radio dispatchers could be obtained. Observers recorded the activities of participants during their work shifts and obtained quantitative measures of volume of work, interruptions, and competing demands. The findings revealed that the volume of work did not have a direct effect on perceived role overload but instead was mediated through interruption.

In explaining the findings of her study, Kirmeyer (1988) relied on the research of Cohen (1980) on attentional capacity. Cohen had proposed that stressors place demands on one's attentional capacity, which may result in cognitive fatigue after prolonged exposure. According to this theory, Kirmeyer suggested that interruptions cause employees to leave tasks unfinished, thus requiring further effort to inhibit attention to them while having to process new information put forth by the interruption. Consequently, this may result in perceptions of 
greater role overload as well as efforts to cope. Although she did not examine stress-related effects, Kirmeyer suggested that interruptions may also have consequences on the psychological well-being, somatic health, and social relations of the individual.

In a lab-based experiment, Zijlstra, Roe, Leonora, and Krediet (1999) had a sample of office workers work on a simulated office for a period of 2 days in order to examine the psychological effects of interruptions. During the text-editing tasks, participants in the experimental group were periodically interrupted by telephone calls from the researcher. Zijlstra et al. found that these interruptions resulted in quicker performance but increased negative mood. In contrast to Kirmeyer's (1988) theoretical explanations, Zijlstra et al. explained his findings using the theory of activity regulation. This theory states that the execution of work tasks is a goal-directed activity, in which actions are produced by executing one's cognitive schemes. When an interruption occurs, the regulation of activity and cognitive schemes is disrupted because the individual must modify his or her action plans. In addition, interruptions put an additional demand on the resources needed for action execution as well as regulation of all activities.

In summary, the extant literature suggests that daily hassles and interruptions are very similar phenomena. Both the theory of activity regulation (Zijlstra et al., 1999) to explain the effects of interruptions and action theory (Zohar, 1999) regarding the effects of daily hassles rest on the premise that activities are goal directed and that disruptions drain the resources for the primary task, which in turn negatively affects employee well-being. Although Kirmeyer's (1988) theoretical explanation of attentional capacity may differ from that of Zohar's, her finding that interruptions also lead to role overload suggests that daily hassles and interruptions have similar consequences on the individual.

\section{Hypotheses}

By likening meetings to interruptions and daily hassles, we propose that meeting load may have negative effects on well-being, similar to the effects of interruptions and daily hassles described previously. To gain a fuller under- standing of meeting load, in the current study we specifically examine what it is about meeting load that affects well-being. Based on related research and partly exploratory in nature, specific hypotheses were generated regarding the effects of these various aspects of the employee's meeting load on daily well-being.

\section{Meeting Frequency}

Given the statistics indicating the inordinate amount of meetings employees have to attend in the current workplace (Mosvick \& Nelson, 1987; Tobia \& Becker, 1990), we began by examining the impact of the sheer number of meetings on the employee. Here, we argue that because individuals must attend meetings in addition to their individual work tasks, meetings have a disruptive nature in the way that daily hassles and interruptions do. Consequently, the more meetings one has to attend, the greater the negative effects.

Hypothesis 1: Meeting frequency will be negatively related to the daily well-being of the employee.

\section{Time Spent in Meetings}

Because meetings vary in the amount of time they consume, it is important to also look beyond their sheer number. That is, one employee may have, say, five short meetings that take up only 2 hours of his or her workday, whereas another individual may have five long meetings that take up 5 hours. Given that role overload refers to having too much to do in the time available (Beehr, Walsh, \& Tabler, 1976; Kirmeyer, 1988), the total amount of time an employee spends in meetings in a day may be more responsible for increasing subjective workload than the sheer number of meetings attended. Furthermore, if, as suggested in the literature, hassles and interruptions are disruptive because they prevent completion of a primary task (Zijlstra et al., 1999; Zohar, 1999), then the more time an employee spends in meetings, the less time he or she has to complete these primary tasks.

Hypothesis 2: The time spent in meetings will be negatively related to the daily wellbeing of the employee. 


\section{Summary}

Overall, our goal is to examine meeting load and its effects on the daily well-being of employees within an individual-based organization. It is not our aim to surmise that meetings are either effective or ineffective, nor is it our intention to examine specific types of meetings. Rather, we fully acknowledge that there are many potential moderators at hand and many possible outcome variables. Our research is a blunt attempt to uncover broad, macro issues of importance as well as to establish the phenomenon of the meeting as a viable research topic. We also acknowledge that other frameworks exist within which the meeting can be studied. The research literature on time management (e.g., Macan, Shahani, Dipboye, \& Phillips, 1990), for instance, would suggest that meetings can be stressors to the extent that having to attend them results in a decreased sense of control for the individual. However, we believe that the research literature on hassles and interruptions is most appropriate given our current aims. In summary, our intent in this article is quite general: to take a research-based look at meetings in order to uncover broad characteristics of the phenomena as they may affect the psychological daily well-being of the employee. We do this by asking whether there is a downside to the high and ever-increasing meeting load experienced by employees.

\section{Method}

\section{Participants}

Of 121 individuals who were notified via regular mail about this longitudinal study, 49 responded. Of these 49 individuals, 37 were selected to be in the final sample because they attended work meetings on a somewhat regular basis (at least three times per week). These individuals completed 5 days of measurements resulting in 185 observations $(37 \times 5$ days $)$ for principal analyses. Our sample size is similar to what is found in other longitudinal research using hierarchical linear modeling (HLM) (e.g., Zijlstra et al., 1999; Zohar, 1999). Participants were full-time employees working in a university-based setting. The work performed by participants ranged widely but was primarily administrative work geared toward enhancing stu- dent campus life. Individuals rather than teams were held accountable for work. The organization's hiring, evaluation, and reward systems were individually based. Workdays were typically from 8 a.m. to 5 p.m. Participants consisted of 21 women and 16 men between the ages of 24 and $60(M=37)$. Average tenure with the organization was 6 years, and average organizational level was 3 (on a scale of 1 to 5). The majority of participants $(85 \%)$ reported having at least one direct report (the average number of direct reports was nine).

\section{Procedure}

A prenotification letter from upper management was first sent to employees to express endorsement of the project. The project was framed as a small longitudinal study about the work environment that would require 5 days of participation. Individuals who completed all questionnaires were entered into a lottery prize drawing for two cash prizes as well as given feedback at the end of the study.

At the beginning of the study, participants were asked to respond to a set of general demographic questions. Participants were then provided with a bound booklet of survey measures containing two sections: a meeting section and a daily well-being section. For the meeting section, participants were asked to complete a brief questionnaire after every work meeting they attended for a period of 1 week. Subsequently, participants were told that a meeting is a workrelated interaction involving two or more individuals. They were also told that a meeting could occur via any modality. We clarified to the participants that a 5-min telephone call or a brief chat with a colleague was not considered to be a meeting. Next, for a period of 5 full working days, participants completed their diary of work meetings and questionnaire of daily well-being (this was completed at the end of a workday). Although all participants completed a total of 5 diary days, days were not consecutive for some individuals (e.g., some missed a day because of absence). To ensure a good response rate, we contacted the participants several times throughout the data collection period to remind them to complete their work diaries, as well as to answer any questions. No problems or concerns were expressed by participants. No participant attrition occurred. 


\section{Meeting Measures}

Meeting frequency. As noted above, participants were instructed to complete a brief questionnaire immediately after every work meeting attended. The number of meetings per workday was simply determined by the number of questionnaires completed (the purpose of each meeting was also noted by participants).

Time spent in meetings. Participants had been instructed to indicate the starting and ending time of each meeting. The time spent in meetings per day was then calculated by summing up the total number of minutes spent in meetings for each day.

\section{Measures of Daily Well-Being}

Fatigue. Fatigue was measured with seven adjectives from the Fatigue Scale in the Profile of Mood States (McNair, Lorr, \& Droppleman, 1981). Participants were asked to rate how each of these adjectives (worn out, fatigued, bushed, exhausted, weary, spent, and tired) described them "at the present moment" (on a 5-point scale, from $1=$ not at all to $5=$ extremely). Fatigue has been found to be related to occupational hassles (Zohar, 1999) and emotional distress (DiLorenzo et al., 1999). In our study, the scale demonstrated high internal consistency (alphas ranged from .94 to .98 across the 5 days).

Subjective workload. Perceptions of work overload were adapted from a scale by Kirmeyer (1988). Participants were asked to rate the extent to which they felt (a) busy or rushed; (b) that the amount of work they did interfered with how well the work was done; (c) pressure in carrying out work duties; and (d) that the amount of work was more than expected (on a 5 -point scale, from $1=$ to no extent to $5=$ to $a$ great extent). It was found to be related to interruptions, with a reported internal consistency estimate (alpha) of .78 in Kirmeyer's study. In our study, the scale demonstrated high internal consistency (alphas ranged from .94 to .98 across the 5 days).

Feelings of productivity. Feelings of productivity were measured with a four-item questionnaire. Participants were asked to indicate the extent to which they thought (a) their workday was productive; (b) they accomplished a lot at work that day; (c) their workday was a waste of time (reverse scored); and (d) their time spent at work that day was useful (on a 5-point scale, from $1=$ to no extent to $5=$ to a great extent). The scale demonstrated high internal consistency (alphas ranged from .85 to .87 across the 5 days).

\section{Analyses}

The data were arranged in a $37 \times 5$ (Subjects $\times$ Days) matrix. Analysis of the hypotheses warranted attention at two levels: day and individual. As noted by Bryk and Raudenbush (1992), HLM is the preferred analytical technique when data structures are nested, such as persons nested within organizational units (e.g., schools) or as in this study, repeated observations nested within persons.

Results

\section{Descriptive Statistics and Covariation Among Dependent Variables}

Participants reported that the primary purpose of most meetings was to solve problems or analyze ideas. Most meetings were face-to-face interactions. Descriptive statistics for daily meeting load are shown in Table 1. Participants had, on average, three meetings per day. The average amount of time spent in meetings for each day was $157.94 \mathrm{~min}$ (slightly over two and a half hours). Descriptive statistics for daily well-being are also shown in Table 1 . Table 2 displays the intercorrelations among the dependent variables at the aggregate level, in which each observation is the mean across the 5 days for each individual.

Table 1

Descriptive Statistics of Daily Meeting Load and Well-Being

\begin{tabular}{lrr}
\hline \multicolumn{1}{c}{ Variable } & \multicolumn{1}{c}{$M$} & \multicolumn{1}{c}{$S D$} \\
\hline $\begin{array}{l}\text { Daily meeting load } \\
\text { Meeting frequency (number of }\end{array}$ & & \\
$\quad$ meetings) & 3.00 & 1.96 \\
$\quad$ Time spent in meetings (min) & 157.94 & 130.06 \\
Daily well-being & & \\
$\quad$ Fatigue & 2.04 & 1.02 \\
$\quad$ Subjective workload & 2.25 & 0.96 \\
$\quad$ Feelings of productivity & 3.59 & 0.78 \\
\hline
\end{tabular}


Table 2

Intercorrelations of Dependent Variables

\begin{tabular}{lccc}
\hline \multicolumn{1}{c}{ Variable } & 1 & 2 & 3 \\
\hline 1. Fatigue & - & $.404 *$ & -.134 \\
2. Subjective workload & & - & .199 \\
3. Feelings of productivity & & & - \\
\hline
\end{tabular}

Note. $N=37$. These are aggregate-level correlations, taken to the individual level. Each observation is the mean across the 5 days for each individual. Hence, daily-level variances are ignored.

$* p<.05$.

\section{Random-Coefficients Regression Results: Testing Daily-Level Hypotheses}

A simple regression approach was taken such that only one well-being variable and one meeting load variable were included at a time in each analysis. Table 3 displays results of each of these HLM analyses. As regression equations are assumed to vary across individuals, these estimated parameters represent the average intercept and slope of the $185(37 \times 5)$ observations. Hence, the intercept indicates the estimated average daily well-being (e.g., fatigue, subjective workload, and so forth) when the meeting load (e.g., meeting frequency, time spent in meetings) is equal to the grand mean.

Similarly, the regression coefficient indicates the estimated average slope representing the relationship between particular meeting load and daily well-being. Results showed some support for our hypotheses that high meeting load is negatively related to daily well-being. Specifically, meeting frequency was related to greater fatigue $(\beta=.09, p<.05)$ and greater subjective workload $(\beta=.06, p<.05)$. However, meeting frequency was not related to feelings of productivity (see Table 3 ). The other indicator of high meeting load, time spent in meetings, was not found to be related to any of the measures of daily well-being (i.e., fatigue, subjective workload, and feelings of productivity).

\section{Aggregated-Level Analyses: Gauging Effect Sizes}

Examining the correlations between aggregated variables may give a sense of the effect sizes, as understood in traditional linear analysis, of these relationships. Pearson correlations were calculated for the relationships that were found to be significant in the above randomcoefficients analyses. For the relationship between meeting frequency and fatigue and between meeting frequency and subjective workload, $r=.42$ and $r=.31$, respectively.

\section{Slopes-as-Outcomes Model Results: Exploring Individual-Level Demographic Variables}

Table 4 displays the estimated variance of the slopes $\left(\tau_{11}\right)$ among the 37 individual regression equations. As noted by Singer (1998), significance tests of these estimates are not very reliable; however, these indices do give an indication of how variable the regression coefficients are across individuals. To attempt to explain the observed variation in the slopes, we included individual-level variables in a slopes-as-outcomes (Level 2) model. Table 4 displays results of the analyses when demographic variables (e.g., gender, organizational level, tenure, supervisory level) served as the Level 2 predictors. The gammas $(\gamma)$ are the regression weights for the individual-level variables on the dailylevel relationship's slopes. Standard errors are reported and used to detect significance. A significant gamma indicates that the individuallevel (i.e., Level 2) variable is moderating the relationship between the daily-level variables. Note that, as with multiple regression in traditional linear analysis, the gammas reflect the partialed covariances of the within-person (i.e., daily-level) variables. Results did not indicate that the strength of the relationships between meeting load (i.e., meeting frequency and time spent in meetings) and daily well-being (i.e.,

Table 3

Hierarchical Linear Modeling Random-Coefficients Regression Results

\begin{tabular}{lccccc}
\hline & \multicolumn{4}{c}{ Meeting load } \\
\cline { 2 - 3 } \multicolumn{1}{c}{ Daily well-being } & \multicolumn{2}{c}{$\begin{array}{c}\text { Meeting } \\
\text { frequency }\end{array}$} & & \multicolumn{2}{c}{$\begin{array}{c}\text { Time spent } \\
\text { in meetings }\end{array}$} \\
\cline { 2 - 3 } & $\beta_{0}$ & $\beta_{\text {it }}$ & & $\beta_{0}$ & $\beta_{\text {it }}$ \\
\hline Fatigue & 2.01 & $.088^{*}$ & & 2.03 & .001 \\
Subjective workload & 2.24 & $.060^{*}$ & & 2.26 & .000 \\
Feelings of productivity & 3.57 & .045 & & 3.58 & .000 \\
\hline
\end{tabular}

Note. $\quad N=37 . \beta_{0}=$ intercept; $\beta_{\mathrm{it}}=$ regression coefficient or slope.

$* p<.05$. 
Table 4

Hierarchical Linear Modeling Slopes-as-Outcomes Model Results

\begin{tabular}{|c|c|c|c|c|c|}
\hline \multirow{3}{*}{$\begin{array}{l}\text { Daily-level (Level 1) } \\
\text { relationships }\end{array}$} & \multicolumn{5}{|c|}{ Individual-level (Level 2) predictors } \\
\hline & & Gender & Org. level & Tenure & Super. \\
\hline & $\beta_{\text {it }}\left(\tau_{11}\right)$ & $\gamma(S E)$ & $\gamma(S E)$ & $\gamma(S E)$ & $\gamma(S E)$ \\
\hline Fatigue and freq. & $.088(.000)$ & $-.089(.079)$ & $-.048(.043)$ & $-.005(.006)$ & $-.051(.102)$ \\
\hline Fatigue and time & $.001(.000)$ & $.024(.026)$ & $.013(.014)$ & $.003(.005)$ & $.069(.048)$ \\
\hline Subjective workload and freq. & $.060(.000)$ & $.053(.061)$ & $-.007(.033)$ & $-.003(.005)$ & $-.100(.078)$ \\
\hline Subjective workload and time & $.000(.000)$ & $.000(.001)$ & $.000(.000)$ & $.000(.000)$ & $-.001(.002)$ \\
\hline Feel. prod. and freq. & $.045(.001)$ & $.012(.058)$ & $-.040(.032)$ & $.004(.005)$ & $-.011(.078)$ \\
\hline Feel. prod. and time & $.000(.000)$ & $.000(.001)$ & $.000(.000)$ & $.000(.000)$ & $-.001(.001)$ \\
\hline
\end{tabular}

Note. $\quad N=37 . \beta_{\text {it }}$ is from the random-coefficients model in which only Level 1 predictors were included. $\tau_{11}=$ estimated variation among the regression coefficients; $\gamma=$ gamma, which indicates the relationship between the individual-level factors and the daily-level beta weights; org. level = level in organization; super. = whether individual supervised others; freq. = meeting frequency; time $=$ time $(\min )$ spent in meetings; feel. prod. = feelings of productivity.

fatigue, subjective workload, and feelings of productivity) were associated with any of the demographic variables (see Table 4).

\section{Discussion}

The primary objective of this study was to examine how meeting load may affect the daily well-being of employees. It was proposed that frequency of meetings and time spent in meetings would be related to daily well-being variables such as fatigue, workload, and feelings of productivity. Below, we discuss the findings and the limitations of this study, propose areas for future research, and discuss the research and practical implications of the current findings.

\section{Frequency of Meetings}

Meeting frequency and fatigue. The frequency of meetings was hypothesized to be negatively related to daily well-being on the basis of the idea that high meeting loads are potential interruptions or hassles to the employee. HLM analyses found that the number of meetings an employee had per day was related to increased daily fatigue as well as greater subjective workload. These findings are essentially consistent with previous studies on daily hassles and interruptions, which found that these phenomena had similarly adverse effects on the individual.

Theoretically speaking, explanations for the finding that meeting frequency was related to greater fatigue can be drawn from Zijlstra et al.'s (1999) theory of activity regulation and Zohar's (1999) action theory, both of which rest on the premise that activities are goal directed and that disruptions drain the resources for the primary task, subsequently resulting in greater fatigue. Given that participants in the current study were working in a predominantly individual-based organization in which they were held individually accountable for their work, having to attend meetings was likely a disruption of their primary tasks. Hence, having more frequent meetings increased this disruptive effect, further draining resources for their primary tasks and resulting in greater fatigue. Certainly, if these meetings that the employee had to attend were not among his or her primary roles and responsibilities, then this disruptive effect would be obvious. However, it is important to note that even if the meetings were part of the employee's primary work, their effects may nevertheless be salient, to the extent that the individual was disrupted from the task at hand (i.e., whatever he or she was working on at the time the meeting started).

Meeting frequency and subjective workload. The theoretical explanation underlying the observed relationship between meeting frequency and increased subjective workload can be drawn from Kirmeyer's (1988) theoretical explanation of attentional capacity to explain how interruptions lead to role overload. According to this theory, having to attend meetings would cause individuals to leave tasks unfinished, thus requiring further effort to inhibit attention to these tasks while having to process new information 
put forth by the meetings, resulting in perceptions of greater role overload. Having to attend more meetings throughout a day, then, would cause not only more tasks to be left unfinished but also more new information that needs to be processed. This would then require even greater effort to inhibit attention to one's primary tasks while having to process even more new information, thereby increasing perceptions of workload.

Meeting frequency and feelings of productivity. Meeting frequency was not found to be related to feelings of productivity. Whereas the theories underlying the effects of interruptions and hassles would predict that meeting frequency affects fatigue and subjective workload, it is not surprising that there was a null finding with feelings of productivity. That is, action theory and the theory of activity regulation and attentional capacity suggest that the disruptive nature of meetings results in drained emotional or mental resources and subsequent fatigue but do not imply much about how a disruption would cause an individual to feel about how much he or she has accomplished. It is as reasonable to suggest that disruptions decrease feelings of productivity (because the individual feels that his or her primary tasks are not completed) as it is to suggest the reverse, that disruptions increase feelings of productivity (because the individual experiences an increase in activity or information). In short, it appears that feelings of productivity are conceptually different from the other dependent variables of daily well-being, such that it is not a consequence of the emotional or psychological drain of resources that results from disruptions, as is fatigue.

\section{Time Spent in Meetings}

Whereas meeting frequency was related to several aspects of daily well-being, the time spent in these meetings did not exhibit any significant relationships. The null finding in regard to time in meetings, although contrary to our hypothesis, is actually consistent with the research literature on interruptions. Zijlstra et al. (1999), in finding that it is the frequency of interruptions and not the amount of time they consume that leads to negative consequences, concluded that "being interrupted several times has a greater effect than one interruption that takes longer" (p. 173).

Theoretically speaking, if meetings place an increased load on the individual's attentional capacity by causing him or her to inhibit attention to current tasks in order to process new inputs (Kirmeyer, 1988), then the frequency of meetings should generate more new inputs that must be processed than should the length of these meetings. Practically speaking, five meetings would generate more and a greater variety of issues, ideas, and concerns that demand the individual's attention than one long meeting that consumes the same amount of time. In summary, although the role overload literature suggests that the time spent in meetings can have effects on the individual, the null findings in regard to this variable are more consistent with the research literature on interruptions.

\section{Limitations and Future Research}

As with any field study, especially in a new research area, limitations exist, prompting the need for much additional research. First, the generalizability of the current findings to other samples and organizational settings must be examined. Participants in the current study were generally administrative employees working in a university setting. It is reasonable to suspect that meetings and, hence, their effects would vary across different types of organizations and employees. For instance, the adverse effects of meetings may be more salient in areas of work that entail a greater deal of time pressures.

Another area of future study lies with the fact that many aspects of the meeting not included here can have effects on the individual. CohenPowless, Rogelberg, and Luong (2003) found that certain meeting design characteristics (e.g., prompt starting and ending times) result in greater attendee satisfaction. The research literature on groups also suggests other meeting aspects that warrant examination (see Levine \& Moreland, 1998; Martens, 1970). For instance, perhaps the number of meeting attendees and the extent to which the individual participated in the meeting affect well-being and other outcomes. Furthermore, as noted by Zijlstra et al. (1999), the disruptive effects of interruption are due not only to the mere change in activity but also to how great of a change occurs between the interruption and the interrupted task. Future 
research should assess how the relevance of meetings to primary work tasks may moderate the relationship between meeting load and well-being.

Future research should examine individuallevel moderators. For instance, potentially important moderators such as the Type A pattern and perhaps some personality variables might significantly moderate the relationship between meeting load and daily well-being. One could speculate, for instance, that the personality dimension of locus of control would moderate the relationship between meeting load and daily well-being, such that individuals with an external locus of control are less likely to be negatively affected by meeting load.

\section{Overall Summary and Implications}

Despite the fact that a number of potential moderators might emerge in future research, it is impressive that a general relationship between meeting load and the employee's level of fatigue and subjective workload was found. In other words, even when meeting quality and other potential moderators are not controlled for, the results seem to suggest that meeting load in and of itself is an important variable to consider when studying employee well-being. In taking heed of these findings, organizations may want to be sensitive to the number of meetings employees are required to attend. Although the scope of the current study suggests only daily-level negative outcomes from having more meetings, these negative effects may compound over time, resulting in decreased satisfaction, poor performance, absenteeism, and even turnover. Limiting meetings may be accomplished via more selective invitation practices, the production of formal guidelines indicating when a meeting is and is not needed, and the establishment of a temporary team member concept (e.g., an employee is part of a team for a limited amount of time).

The present study also has implications for research. First, by drawing parallels between the research on interruptions and that on daily hassles, the present study indicates that these are similar phenomena that may be examined on common theoretical grounds. Future research on any of these phenomena should pull together and reference previous research on hassles and interruptions as a single body of literature. Ad- ditionally, the present study introduces the meeting as a potential disruption, further contributing to the research literature on hassles and interruptions by including the meeting as one more type of hassle or interruption that can occur for individuals.

\section{References}

Beehr, T. A., Walsh, J. T., \& Tabler, T. D. (1976). Relationship of stress to individually and organizationally valued states: Higher order needs as a moderator. Journal of Applied Psychology, 61, 4147.

Bryk, A. S., \& Raudenbush, S. W. (1992). Hierarchical linear models: Applications and data analysis methods. Newbury Park, CA: Sage.

Butterfield, E. C. (1964). The interruption of tasks: Methodological, factual, and theoretical issues. Psychological Bulletin, 62, 309-322.

Caspi, A., Bolger, N., \& Eckenrode, J. (1987). Linking person and context in the daily stress process. Journal of Personality and Social Psychology, 52, 184-195.

Cohen, S. (1980). Aftereffects of stress on human performance and social behavior: A review of research and theory. Psychological Bulletin, 88, 82108.

Cohen-Powless, M. A., Rogelberg, S. G., \& Luong, A. (2003, April). Understanding meeting satisfaction: A focus on design characteristics. Poster session presented at the Seventeenth Annual Conference of the Society for Industrial and Organizational Psychology, Orlando, FL.

DiLorenzo, T. A., Bovbjerg, D. H., Montgomery, G. H., Valdimarsdottir, H., \& Jacobsen, P. B. (1999). The application of a shortened version of the Profile of Mood States in a sample of breast cancer chemotherapy patients. British Journal of Health Psychology, 4, 315-325.

Emmons, R. A. (1986). Personal strivings: An approach to personality and subjective well-being. Journal of Personality and Social Psychology, 51, 1058-1068.

Emmons, R. A. (1991). Personal strivings, daily life events, and psychological and physical well-being. Journal of Personality, 59, 453-472.

Ganster, D. C., \& Schaubroeck, J. (1991). Work stress and employee health. Journal of Management, 17, 235-271.

Jamal, M. (1990). Relationship of job stress and Type-A behavior to employees' job satisfaction, organizational commitment, psychosomatic health problems, and turnover motivation. Human Relations, 43, 727-738. 
Kirmeyer, S. L. (1988). Coping with competing demands: Interruption and the Type A pattern. Journal of Applied Psychology, 73, 621-629.

Koch, J. L., Tung, R., Gmelch, W., \& Swent, B. (1982). Job stress among school administrators: Factorial dimensions and differential effects. Journal of Applied Psychology, 67, 493-499.

Levine, J. M., \& Moreland, R. L. (1998). Small groups. In D. Gilbert, S. Fiske, \& G. Lindzey (Eds.), The handbook of social psychology (4th ed., pp. 415-469). Boston: McGraw-Hill.

Macan, T. H., Shahani, C., Dipboye, R. L., \& Phillips, A. P. (1990). College students' time management: Correlations with academic performance and stress. Journal of Educational Psychology, 82, $760-768$.

Martens, R. (1970). The influence of participant motivation on success and satisfaction in team performance. Research Quarterly, 41, 510-518.

McNair, D. M., Lorr, M., \& Droppleman, L. F. (1981). Profile of Mood States manual. San Diego, CA: EdITS.

Mintzberg, H. (1973). The nature of managerial work. New York: Harper \& Row.

Mosvick, R., \& Nelson, R. (1987). We've got to stop meeting like this! A guide to successful business meeting management. Glenview, IL: Scott Foresman.

Motowidlo, S. J., Packard, J. S., \& Manning, M. R. (1986). Occupational stress: Its causes and conse- quences for job performance. Journal of Applied Psychology, 71, 618-629.

Schwartzman, H. B. (1986). The meeting as a neglected social form in organizational studies. In B. M. Staw \& L. L. Cummings (Eds.), Research in organizational behavior (pp. 233-258). Greenwich, CT: JAI Press.

Singer, J. (1998). Using SAS PROC MIXED to fit multilevel models, hierarchical models, and individual growth models. Journal of Educational and Behavioral Statistics, 24, 323-355.

Tobia, P. M., \& Becker, M. C. (1990). Making the most of meeting time. Training and Development Journal, 44, 34-38.

Zijlstra, F. R., Roe, R. A., Leonora, A. B., \& Krediet, I. (1999). Temporal factors in mental work: Effects of interrupted activities. Journal of Occupational and Organizational Psychology, 72, 163-185.

Zohar, D. (1997). Predicting burnout with a hasslebased measure. Journal of Organizational Behavior, 18, 101-115.

Zohar, D. (1999). When things go wrong: The effect of daily work hassles on effort, exertion, and negative mood. Journal of Occupational and Organizational Psychology, 72, 265-283.

Received July 12, 2004 Accepted December 13, 2004 